\title{
Compaction behaviour of plaster of Paris dewatered- and air dried-Nigerian clay
}

\author{
C S NWOBODO \\ School of Enginesting and Engineering T'echnology, Federal University of Technology, P.M.B. 1526, Owerri, \\ Imo State, Nigeria
}

MS received 18 August 1997

\begin{abstract}
The effects of compaction pressure on the green bulk density and porosity of Nigerian clay were examined over a range of pressure from 47.2 to $157.3 \mathrm{MPa}$. An exponential behaviour was found between presser relative density and compaction pressure, the logarithm of relative density increasing with compaction pressure.

An exponential behaviour was also found between compaction pressure and true porosity, the latter decreasing as the logarithm of compaction pressure increased.

Finally, empirical equations relating to true porosity and compaction pressure and also the relationship between relative density and compaction pressure, are presented.
\end{abstract}

Keywords. Compaction behaviour; plaster of Paris; Nigerian clay.

\section{Introduction}

The compaction behaviour (Dynys and Halloran 1983) of ccramic powders is strongly influenced by the state of aggiomeration of the powder. With increasing applied pressure the density of the powder column will increase, or its porosity will decrease. Several workers (Yu Balshin 1938; Seelig and Wulff 1946; Bockstiegel and Hewing 1965) have studied the relationship between applied pressure and the density or porosity of powder compact, and have attempted to establish mathematical relationships between pressure and average relative density. For dry compaction of nonplastic materials, the agglomerate state of primary industrial relevance involves nonaggregated powder agglomerated into powder free-flowing granules by spray-drying with a binder. Clay in itself has binding characteristics.

The object of this study is to investigate the effect of compaction pressure on the green bulk density and true porosity of Nigerian clay* suitable for refractory brick manufacture.

\section{Experimental}

The clay used in this study consisted basically of clay substance, vegetable matter and free silica. The asreceived clay was wet-sieved to pass 200 mesh. The resulting slip was allowed to settle for $48 \mathrm{~h}$ and the supernatant licpuid decanted. The siurry was then

\footnotetext{
"Clay is from Alikpo in Abial State of Nigeriu
}

dewatered on a plaster of Paris bat and dried in air to a leather-hard condition. The resulting lumps were crushed to powder containing $2.3 \%$ moisture.

The clay powder was compacted using a $19 \mathrm{~mm}$ internal diameter steel die and punch set. The punch and die were hubricated with engine oil to lessen die-wall friction effects. Compacrion was performed on a Buehler Ltd laboratoty mounting press at pressures of $47.2,62.9$, $94.4,110.1,125.8,141.5$ and $157.3 \mathrm{MPa}$. Ten clay discs were compacted at each pressure.

The true specific gravity of the clay powder was determined by the evacuation method (Chesters 1974). Three concordant readings were obtained and an average value taken.

The green bulk density and apparent porosity of the clay compacts were determined by evacuation method with kerosene as the liquid medium. The bulk density, $D$ was calculated using the relationship:

$$
D=\frac{W_{d}}{W_{s}-W_{p}} \times D_{s},
$$

where $W_{u}$ is the dry mass, $W_{s}$ the soaked nass, $W_{\mathrm{s}}$ the suspended mass and $D_{\mathrm{s}}$ is the density of the liquid medium.

The apparent porosity (AP), was calculated using the relationship:

$$
\mathrm{AP}=\frac{W_{\mathrm{s}}-W_{4}}{W_{\mathrm{s}}-W_{\mathrm{p}}} .
$$

The true porosity (TP), was also calculated using the relationship: 


$$
\mathrm{TP}=1-\frac{D}{D_{0}},
$$

(3) the range of compaction pressures used in this investigation. Table 1 lists the average bulk densily against the corresponding compaction pressure. Figure 1 shows the semilogarilhmic plot of the relative density, $D / D$ against compaction pressure based on least squares analysis.

\subsection{Effect of compaction pressure on green porosity}

The relationship between the compaction pressure and green porosity exhibits a straight line on a semilogarithmic plot, within the range of compaction pressures used in this investigation. Table 2 lists the average green porosity as a function of compaction pressure. Figure 2 shows the semilogarithmic plot of compaction pressure against green porosity (volume fraction).

The inost prominent features of this investigation are the linear relationships resulting from the semilogarithmic plots of relative density vs compaction pressure and true porosity vs compaction pressure. This means that the bulk of the compaction data, from 72 to $81 \%$ theoretical density, can be represented simply by the empirical equation

$$
D=D_{00} \exp (k P),
$$

where $k$ is empirical slope, $P$ the compaction pressure,

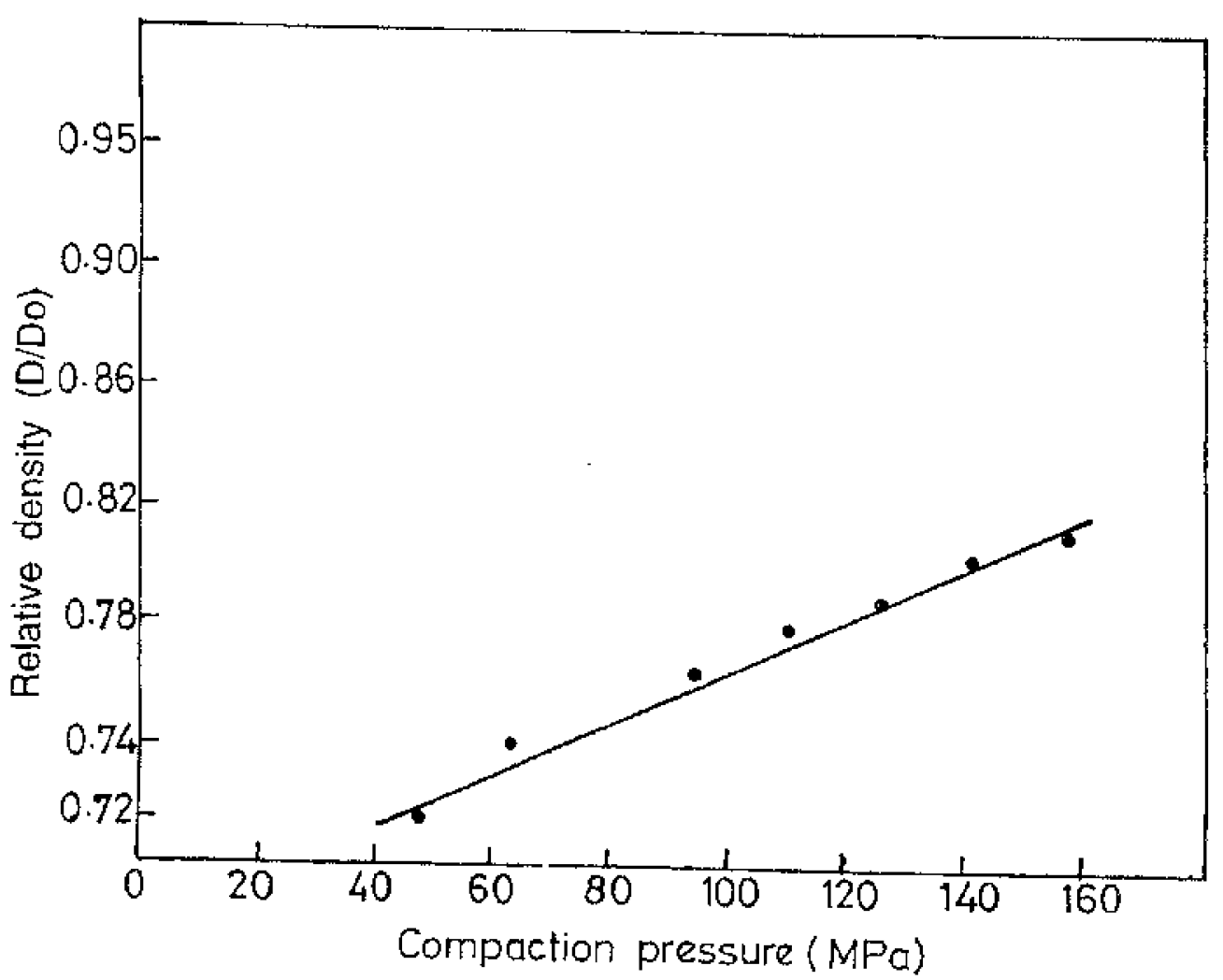

Figure 1. Effact of compaction pressure on relaljve densily. 
$D$ the density of compact at pressure, $P$ and $D_{17}$ the true density of the clay powder.

The $D / D_{10}$ and $F$ values obtained in this study were highly correlated. A plot of $\ln D / D_{0}$ vs $P$ could be fit by a straight line with a regression coefficient of 0.9862 . Increasing the compaction pressure from 47.2 to 157.3 $\mathrm{MPa}$ increases the bulk density from 72 to $81 \%$ of the theoretical density.

Again, increasing the compaction pressure from 47.2 to $157.3 \mathrm{MPa}$ decreases the true porosity, expressed as a volume fraction, from 0.278 to 0.190 . This allows the buik of the compaction data, from 0.278 to 0.190 true porosity, to be represented simply by the empirical equation:

Table 2. Efted of compaction pressure on green porosity.

\begin{tabular}{|c|c|c|c|c|}
\hline Designation & $\begin{array}{c}\text { Compaction } \\
\text { pressure } \\
\text { (MPa) }\end{array}$ & $\begin{array}{c}\text { No, of } \\
\text { specimens }\end{array}$ & $\begin{array}{l}\text { Average } \\
\text { green } \\
\text { porosity } \\
\text { (vol. } \\
\text { fraction) }\end{array}$ & $\begin{array}{l}\text { Standard } \\
\text { deviation }\end{array}$ \\
\hline P1 & $47 \cdot 2$ & 10 & 0.278 & 0.0049 \\
\hline P2 & 62.9 & 10 & 0.256 & 0.0039 \\
\hline P3 & 94.4 & 10 & 0.242 & 0.0021 \\
\hline P4 & 110.1 & 10 & 0.214 & 0.0025 \\
\hline P5 & $125 \cdot 8$ & 10 & 0.203 & 0.0020 \\
\hline P6 & 141.5 & 10 & 0.196 & $0-0044$ \\
\hline P7 & $157 \cdot 3$ & I0 & 0.190 & 0.0033 \\
\hline
\end{tabular}

$$
P=P_{0} \exp \left(-b_{P}\right)
$$

where $P$ is the compaction pressure, $P_{0}$ the compaction pressure at zero porosity, $b$ the empirical slope which is a constant for the material and $p$ the volume fraction porosity. The straight line obtained from a semilogarithmic plot of pressure, $P$ vs volume fraction porosity, $P$ has a regression coefficient of $0-9831$. This suggests that the pressure-porosity relationship is well correlated. This is anticipated by the Duckworth (1953) equation in the discussion of Ryshkewitch's paper.

However, it should be noted that the mechanics of dry powder compaction is complex in its details (Broese Van Groenau 1981), and unclear in its foundations (Onoda and Urban 1978), and therefore alt equations must be considered empirical rather than based on the principles of mechanics. Nevertheless they are quite uselul for the purpose of interpolating green densities and/or porosities as a function of compaction pressure.

The effect on green density and porosity of compaction pressures less than 47.2 MPa and greater than $157.3 \mathrm{MPa}$, was not investigated in this study. The extrapolated density is $1.79 \mathrm{~g} \mathrm{~cm}^{-3}$ as against the tap density $1.31 \mathrm{~g} \mathrm{~cm}^{-3}$. It is anticipated that the porosity will increase exponentially with a decrease in compaction pressure.

When semidry powders are pressed, there must be incomplete transmission of pressure because a proportion of the thrust is taken up in overcoming the friction the

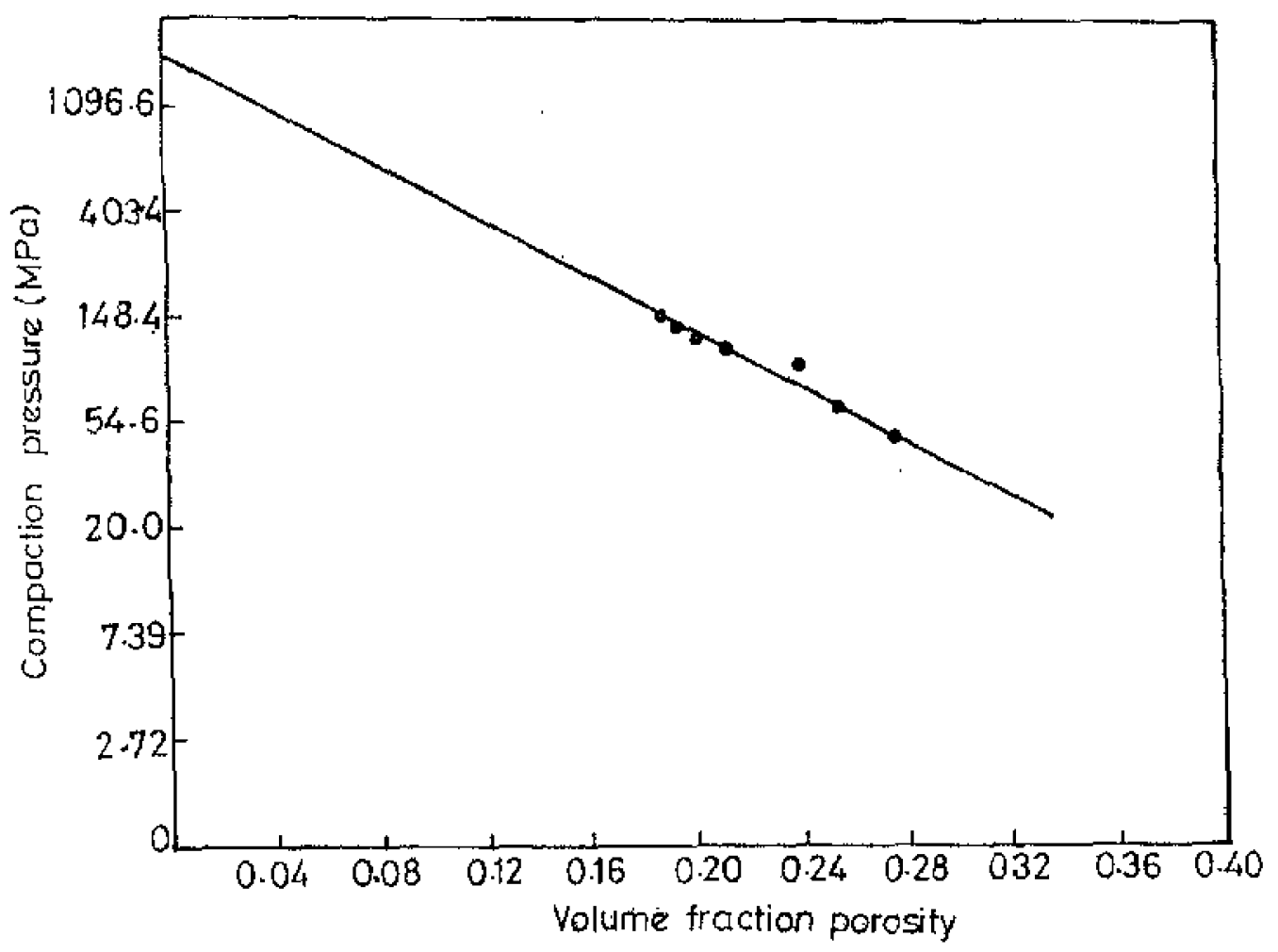

Figure 2. Elfect of coinpaction pressure on green porosity. 
grains exert on each other and on the sides of the die. Shaxby and Evans (1923) have shown that the pressure decreases with the distance from the surface layer at a rate directly proportional to the coefficient of friction of the particles on the walls of the die and to the externally-applied pressure but inversely proportional to the radius of the die (assumed cylindrical).

Consequent on this pressure gradient, the buik density in the pressed compact must vary with the depth, it accordance with the logarithmic relationshif already establisbed.

The apparent porosity of sintered firebicks varies liom $9 \%$ (very low) to $22.5 \%$ while the bulk density varies from 1.96 to $2.36 \mathrm{~g} \mathrm{~cm}^{-3}$. lrom the compaction dath a suitable compaction pressure corresponding to a given green bulk density or porosity of refractory bricks made from the clay used in this study can be estinated. It should be noted that the porosity of the sintered material will decrease while the bulk density will incrcase. This means that within the range of compaction pressures used in this sudy, sintered refractory bricks having porosities between 1.96 and $2.36 \mathrm{~g} \mathrm{~cm}^{-3}$ can be produced from the Nigerian clay used.

\section{Conclusion}

The effect of compaction pressure on the bulk density and porosity of the Nigerian clay can be described by empirical expressions relating logatthn of relative densicy to compaction prossure and also relating logarithm of compaction pressure to true porosity before sintering.

The empirical equation desctibing the effect of compaction pressule on the porosity is similar to the Duckworth equation in the discussion of Rystakewilch's paper.

The rclationship between the bulk density, $D$ and the compaction pressure, $P$ car be represented by

$$
D=D_{6} \exp \left(1.07 \times 10^{-7} P\right) \text {, }
$$

where $D_{0}$ is the true density.

The relationship between the compaction pressure, $P$ and the volume fraction of porosity, $p$ can be represented by

$$
P=1816 \exp (-1294 p)
$$

The compaction data for this clay sample has been used to produce refractory bricks by dry pressing prior to sintering.

\section{Acknowledgement}

This work was a private research. The author thanks Prof, $V O$ Nwoko, Federal University of Technology, Owerri for providing research facilities at the time of this study.

\section{References}

Bockstiegel $\mathrm{G}$ and Hewing $\mathrm{J}$ I965 Critical review of the fiterature on the densification of powders in rigid dies (Arch Ejsenhuttenwesen) Vol. 36, pp 751-767

Broese Van Groenau A 1981 J. Powder Technol. 2822

Chesters I H 1974 Refractories for iron and steel making: Determination of me specific yravity (The Metals Society) p. 428

Duckworth W $1953 \mathrm{~J}$. Am. Ceran. Soc. 3668

Dynys $\mathrm{F}$ W and Hallom $\mathrm{J} \mathrm{W}$ 1983 $/$. Am, Cerom, Soc. 66 655

Onoda $\mathrm{G} Y$ and Utban $\mathrm{F} 1978$ Mechanics of sfress and green density variation in ceranie powder compacts: A witical assesument, in Proc. of int symp. on factors in the densficotion and sintering of oxide and non-oxide ceranics (eds) S Somiya and S Sailo (Tokyo: Tokyo Institute of Tachnology) pp 93-100 Sedig R P and Wulft J 1946 Trars: ACME 166492

Shaxby J ff and Evans J C 1923 Trans. Foratay Soc. 1960 Yo Balshin M 1938 Theory of compacting (Vestnik Metalloprom) Vol. 18, fP 127-137 